\title{
Usability Perceptions of the Madrasati Platform by Teachers in Saudi Arabian Schools
}

\author{
Wesam Shishah \\ College of Computing and Informatics \\ Saudi Electronic University, Riyadh, Saudi Arabia
}

\begin{abstract}
As a result of the COVID-19 pandemic, the Saudi Ministry of Education launched the Madrasati Platform for distant teaching and learning for schools. Therefore, recognizing the design and the usability challenges that are linked to this new platform is significant. This paper reports the results of a study that examines the usability level of the Madrasati Platform from the perspectives of the schoolteachers in Saudi Arabia. It also investigates the usability issues that teachers faced when using the platform. A total of 759 teachers responded to the Computer System Usability Questionnaire (CSUQ). Semi-structured interviews were also conducted with ten teachers. The findings of the study indicated that the usability of the Madrasati Platform for the schoolteachers is inadequate and needs to be improved further. Navigation issues were the most reported issues by the participants. Finally, the paper presents some recommendations for improving the usability and experience with the Madrasati Platform.
\end{abstract}

Keywords-Usability; Madrasati Platform; e-learning; Saudi Arabia; schools

\section{INTRODUCTION}

As information and communication technology has rapidly spread over the world, the internet has become an increasingly vital means of connection between educational institutions and their students. Schools, colleges, and universities are increasingly using e-learning as a teaching and learning tool. E-learning has numerous clear advantages over traditional learning methods, not the least of which is its flexibility to be used at any time and in any location. Furthermore, it creates environments that allow students to be active participants in their learning, to acquire independence, to become selfreflective, and to collaborate with others, as well as provide a lot of options for creative teaching approaches [1].

As a result of these advancements in internet technology, learning management systems (LMS) have emerged. LMSs are robust software platforms for managing educational activities, with the goal of assisting instructors in conveying knowledge to students and speeding up the learning process. LMSs can be used by educational institutions to store, administer, and distribute educational content as needed [2]. In recent years, a variety of learning management systems (LMS) have emerged, each with its own set of features and benefits for users. Blackboard (BB), Desire2Learn (D2L), and Moodle are examples of learning management systems. By 2025, the global market for LMSs is expected to grow from 13.4 billion dollars in 2020 to 25.7 billion dollars [3].
There is an increasing recognition that high levels of usability are required for LMS development and application to be successful. Instructors save time with useable LMS because they can design and deliver courses more quickly and efficiently. Tutors and students can focus on course content rather than dealing with troublesome technologies, which improves the learning experience. Nonetheless, some studies suggest that the design of LMSs has received little attention, resulting in major usability issues [4]. As a result, institutions considering introducing any LMS must carefully examine its usability before deploying it.

As an emergency move to prevent the spread of the COVID-19 epidemic, schools and colleges around the world have closed face-to-face instruction and sent students home. Saudi Arabia, like many other countries across the world, employed remote learning via virtual classroom as a preventative step to protect teachers and students from COVID-19. In the face of COVID-19's rapid spread, schools were forced to choose between postponing lessons for an unknown period or introducing online classes right away [5]. Consequently, the Ministry of Education (MOE) established the Madrasati Platform, which is an LMS that facilitates teaching and learning in Saudi schools. It became obligatory for schools to use the Madrasati Platform to introduce courses. At the same time, teachers were learning how to use this platform. Traditionally, they had always used face-to-face instruction as a method of delivery. However, this transition to online learning has highlighted concerns about the quality of education [6].

Following the onset of COVID-19, this platform had just recently been adopted in Saudi Arabia's educational system so research on the platform's usability is limited. The author in [7] conducted the only study we found that evaluated the Madrasati Platform's usability. They evaluated the platform using different web diagnostic tools and measures and did not include any target groups of the Madrasati Platform such as schoolteachers and students. To the best of our knowledge, no studies have focused on evaluating the usability of the Madrasati Platform from the perspective of a target user of the platform as this study does; therefore, this study addresses the following research questions:

- Research Question 1 (RQ1): What is the usability level of the Madrasati Platform from the perspective of schoolteachers in Saudi Arabian? 
- Research Question 2 (RQ2): What are the major usability issues that teachers faced when using the Madrasati Platform?

\section{LITERATURE REVIEW}

\section{A. Covid-19 and Education in the Kingdom of Saudi Arabia}

Saudi Arabian schools and universities have been forced to convert all their regular face-to-face classes to online classes as a result of the COVID-19 outbreak. Saudi Arabia's Ministry of Education made this decision on March 8, 2020. The Ministry responded to the closure decision by issuing a document called "The COVID-19 Pandemic Protocols" for universities to follow, in which online teaching became the primary form of instruction. Students were not permitted on campus, and no staff or faculty gatherings were permitted [8].

Since then, students and teachers have only been able to communicate via online platforms such as Blackboard and Zoom (an online video communications application). Thousands of teaching members were compelled to offer their lessons in front of a computer display, with students viewing from home using the internet. This significant transformation occurred in a short period of time. Due to the quick global development of COVID-19, the switch to online teaching was adopted in 61 more countries by March 13 [9].

Saudi Arabian universities have offered limited online education choices as part of an open education network since the early 2000s. Because the information and network technology infrastructure were not well developed, the number of online courses grew slowly over time. Furthermore, due to a lack of computer access for some students and inadequate computer skills among some faculty members, students and faculty members exhibited limited interest in online instruction [8]. Prior to the COVID-19 epidemic, the quantity of online courses compared to face-to-face courses was very low [10].

Shifting all current courses to online platforms in a matter of days was a significant issue. In addition, creating and delivering online courses involves precise lesson planning, specialized training, technology tools, and an IT team's help [8]. The unexpected breakout of COVID-19, on the other hand, revealed the lack of online teaching skills among faculty members as well as the unpreparedness for an entirely online approach among departments and schools. Students, on the other hand, showed fewer problems with online technologies and platforms, but they experienced issues with self-control, offline learning environments, and learning behavior [11], [12].

In Saudi Arabia, education is given a lot of attention and care by the government. Dr. Hamad bin Mohammed alSheikh, the Saudi Minister of Education, announced that Saudi Arabia began offering online education years ago, but the systems were recently updated in response to the coronavirus outbreak [13]. Since the start of this shift, the Ministry of Education (MoE) has introduced five virtual learning alternatives that could be accessed at any time and from any location. These are possibilities available to those who do not have access to the internet via television. Students can access their lectures via iEN TV channels, iEN's Youtube channel,
iEN's educational portal, Future Gate, and the unified education database [14]. Moreover, the Ministry of Education has been broadcasting educational materials for all grades on television and through social media. Also, approximately 127 teachers and administrators have been nominated to teach regular classes in 112 enlightening courses on various television channels (broadcasting nationwide from a classroom in Riyadh) [15].

Furthermore, the Ministry of Education prepared to launch the new Madrasati Platform by the beginning of the 2020 academic year. The Madrasati Platform allows teachers to construct virtual classes and provide students with a wide range of content, including presentations, educational videos, textbooks, exercises, and courses at various levels: elementary, intermediate, and secondary [16]. The Ministry of Education has also created several educational policies to help students effectively utilize these electronic and educational opportunities. For example, morning hours are allocated to intermediate and secondary students, while afternoon hours are allocated to elementary students, so that parents would be able to follow up with the students to provide help with their distant learning in the evening [17]. Al Mayman points out that the MoE is working closely with other ministries to ensure that every student has the necessary tools and resources to successfully complete the school year via distant learning. The objective is to assist students who lack internet access, or who do not have any devices to access the platform by broadcasting lessons during school time [16].

AlSalih points out that the Ministry of Education is working in cooperation with experts in international organizations to conduct an extensive validating assessment study on distant learning in universities and schools, during and after the pandemic [18]. Therefore, online learning is not just a temporary solution for this period. The Saudi Minister of Education has declared that online learning could eventually become a strategic choice for Saudi Arabia and not just an alternative in response to the coronavirus crisis [19].

Many studies have evaluated the effect of COVID-19 on education in Saudi Arabia [8], [15], [20]. In a study conducted in Saudi Arabia's elementary schools, researchers investigated the teachers and the students' perspectives of e-learning. Overall, teachers and students in primary schools expressed positive attitudes toward e-learning [20]. Another study conducted in Jubail Industrial College reported that E-learning according to many teachers, saves time and energy when it comes to revising and modernizing teaching materials. A small percentage of teachers consider e-learning to be an additional liability because they are not confident in their capacity to handle the technical needs during the pandemic. The majority of teachers were enthusiastic about the idea of incorporating new technologies and approaches into the classroom. Teachers, on the other hand, pointed out that proper training and workshops are essential to improve the effectiveness and efficiency of e-learning activities [15].

\section{B. Madrasati Platform}

As abovementioned, the Madrasati Platform was established by the Ministry of Education (MoE) as a result of the decision by the Saudi government to close all public 
schools in the country. Originally, the schools were to use the Madrasati Platform for the first seven weeks of the first semester of the 2020 academic year. As the coronavirus situation continued, the MoE announced that schools are to continue using the platform until further notice. The Madrasati Platform is an e-learning environment consisting of many tools that support the teaching and learning process for all education levels from the 1 st to the 12th grade. It also helps in following the lesson plans and achieving educational aims and objectives set by the curriculum. Furthermore, it aids students in acquiring skillsets, values and new knowledge, and at the same time being compatible with the digital needs and requirements of the present and future [21].

The Madrasati Platform features a package of educational tools to assist the teaching and learning process. The platform features a virtual classroom that enables teachers and students to meet via virtual conference or at any suitable time via recorded lessons. In addition, it includes the Microsoft Office (365), which includes email client, Teams, and a variety of networks for communication amongst learners, teachers, or parents. The platform also provides educational books, videos, and cartoons, containing 450,000 electronic lesson plans and 45,000 educational contents. Moreover, it contains tools related to lesson planning and design that allow teachers to design lessons with equality and diversity in mind. Teachers can also design assignments or online tests using this platform. The platform also has test-banks that contain in excess of 100,000 questions for evaluation and measurement of cognitive and educational achievements [21], [22].

By the end of the first semester in 2020, the Madrasati Platform facilitated more than 89,000 virtual lessons for private and public schools in Saudi Arabia, with about 489 million visitors. Moreover, teachers created more than 2.5 million electronic test forms using this platform during the first semester, while students submitted more than 15 million assignments and made more than 10 million enquiries to teachers [23].

Madrasati's features and performance are quite similar to those of commercial providers like Moodle, Blackboard, and Canvas. Madrasati Platform, on the other hand, is an internally built LMS that is designed by an organization rather than one that is purchased and deployed by a commercial company.

Khanfar (2020) investigated the most significant obstacles encountered by female teachers in Eastern Region public schools in Saudi Arabia during the coronavirus pandemic. She concluded that the most important challenges were the skills and the infrastructure required in using the Madrasati Platform based on 375 female teachers' opinions [5]. However, as discussed above, the Madrasati Platform incorporates a variety of Microsoft Teams features which enables safe virtual classrooms for learners to interact with their teachers when it comes to class homework and e-activities [21]. In another study, [22] concluded that most teachers believed that the platform would reduce the teachers' responsibilities in future, especially in theoretical materials, and hoped to continue teaching using this platform even after the coronavirus pandemic has ended. The teachers also reported that due to the difficulties during the registration process, some students and teachers were hesitant to use the platform when it was first introduced [22].

Moreover, the teachers also indicated that using the Madrasati Platform has many advantages such as ease of teaching, an integrated platform, online tests and assignments. The platform also saves time, effort, and data; builds learners self-reliance; reduces financial waste, and traffic congestion. Nonetheless, the Madrasati Platform also has several disadvantages and negative aspects, including less interaction, no direct communication between teacher and student, and a decrease in students' attention levels and lack of flexibility in tackling them. Also, there is the issue of evaluating outstanding students, which led them to decide not to attend the asynchronous virtual classroom (iEN channels or other recorded video) and only concentrating on synchronously virtual (live) classroom on Teams. Finally, there are some technical issues with the suspension of the platforms' system [22].

\section{Usability of e-Learning}

According to [24] and [25], current e-learning systems are more concerned with the course material than with the design of the content. The majority of e-learning research studies focus on the information quality rather than the design's usability [26], [27]. The main problem faced by e-learning designers is the creation of sophisticated technologies that allow learners to easily endure their learning activities regardless of time or location [28]. According to [29], the interface is the most important aspect in the user's first impression.

Human-Computer Interaction (HCI) is mostly accomplished using interfaces. This defines the e-learning tool's learning environment [28]. In the e-learning environment, interface design has an impact on the student and instructor's ability to collaborate effectively [30]. According to [31], usability is the most important component in HCI. The ability to use the system in a simple manner is referred to as usability [32]. Total usability, according to [33], is comprised of a few essential components, including learnability, efficiency, memorability, error frequency, and subjective satisfaction.

Perceived usability is an important component of the higher-level construct of us-ability [34]-[37]. The Computer System Usability Questionnaire CSUQ [38] and the System Usability Scale [39] are two of the most widely used standardized questionnaires for assessing perceived usability. They were created independently in the 1980s by IBM and DEC and released in the mid-1990s. According to recent studies, the SUS and CSUQ questionnaires are highly associated and appear to be assessing the same thing, probably perceived usability [40], [41].

Many studies on evaluating usability of e-learning websites have been undertaken in Saudi Arabia [42]-[45]. For example, Al-Omar (2017b) investigated and assessed the internal and exterior usability aspects of 12 university websites in Saudi Arabia that offer distant education courses and found that these websites are reliable but violate basic usability criteria. Also, [43] and [45] investigated the usability 
of JUSUR LMS using usability techniques based on satisfaction surveys. The findings revealed that the investigated students liked JUSUR LMS and found it simple to use. However, the system has some technical and functional issues that make it difficult to use. Moreover, [4] evaluated the design user interface to prove their hypothesis that Blackboard LMS is accessible and usable by teachers at King Saud University by questionnaires. The result was that the software is simple to access and use. Also, [46] recently published an empirical study in Saudi Arabia on Saudi students' preferences for Moodle and Blackboard systems. In their study, the authors compared three metrics: user interface, download and upload service, and materials organization. As a result, in terms of usability, students preferred the Moodle learning management system over Blackboard. Furthermore, a recent paper presented the findings of a study that investigated the usability of the Blackboard system from the perspective of academics at Umm Al-Qura University in Saudi Arabia, using two of the most used usability measures, SUS and CSUQ. The study's findings revealed that Blackboard's usability is insufficient and needs to be improved [40].

Furthermore, the content accessibility and usability of the Madrasti Platform were evaluated by [7]. In the examination, different web diagnostic tools and measurements based on Nielsen usability criteria were employed. The measures broke links compliance with WCAG guidelines. The evaluation was conducted on only 5 main pages in a student account which are the Sign in page, Home page, My courses page, My homework page and My schedule page. According to the findings, the Madrasti Platform is considered inaccessible by some disabled users. Also, the Madrasti's usability is considered as low [7].

\section{Methodology}

Both qualitative and quantitative data were collected in this study. As a result, both quantitative and qualitative approaches were used in the data analysis. This section will describe the methods used which are survey, semi-structured interview, and thematic analysis.

\section{A. The Questionnaire}

The study was conducted using the questionnaire as a data gathering tool. Questionnaires are one of the most used data collection techniques, across all fields of research, not just usability studies. The questionnaire was identified as the most appropriate for the study because large amounts of data could be collected in real time, it is familiar to several respondents, and it is easier to administer [47]. The questionnaire included 24 questions in three sections. The first section includes 4 questions that are related to age, gender, school level in teaching and region of the kingdom. The second section also includes 4 questions that related to teaching experience, whether an e-learning system has been utilized previously, device used and the internet browser. The third section of the questionnaire includes 16 questions (see Fig. 1) which are related to Computer System Usability Questionnaire (CSUQ). These questions produce four scores (one overall score and the other three are subscales). The following are the rules for determining these scores:
- Overall: average of the answers to questions 1-16 (all questions).

- The Usefulness of the System: average of the answers to questions 1-6.

- Information Quality: average of the answers to questions 7-12.

- Interface Quality: average of the answers to questions 13-15.

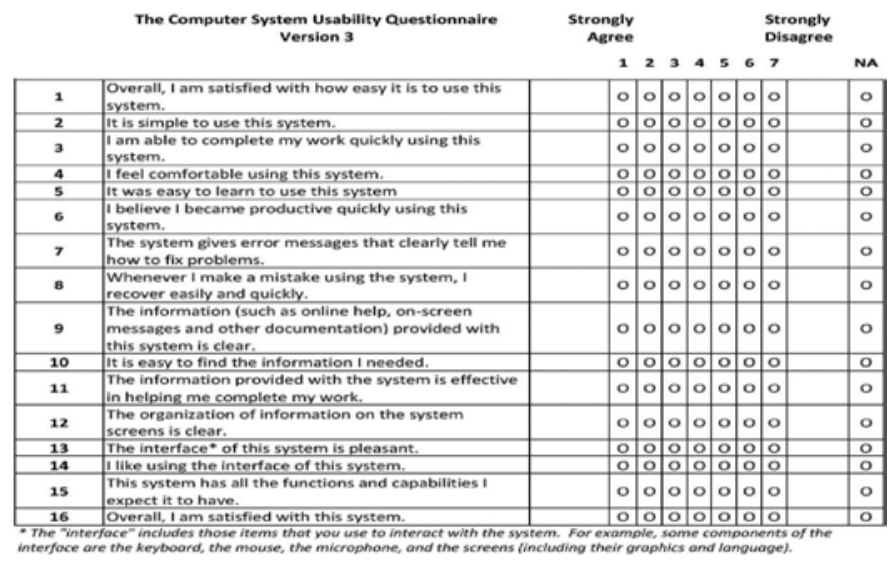

Fig. 1. The CSUQ[36].

The resulting scores range from 1 to 7 , or NA (not applicable), with lower scores indicating the higher agreement level of the user. The CSUQ scales had high reliability, with coefficient alphas exceeding .89 for all scales. [38], [40].

The respondents were given the questionnaire in their native language (Arabic). The Arabic version of the CSUQ was created using the translation approach as used by [48]. Google Forms was used to host the questionnaire online. The questionnaire was designed for teachers who were familiar with the Madrasati Platform in Saudi schools for all grade levels, as stated on the welcome page of the questionnaire. They were also informed that participation in the study was completely optional, and they could withdraw at any time. Also, to ensure clarity, three teachers piloted the questionnaire before it was distributed. After the questionnaire distribution, statistical analyses were conducted to analyze the data using the software - Statistical Package for the Social Sciences (SPSS).

\section{B. Semi-structured Interview}

Following the questionnaire, semi-structured interviews were conducted. They provided the flexibility we required for the interviews. They allowed us to focus on the most pressing usability issues about interface and design, as well as ask follow-up questions. As a result, we received detailed feedback on specific concerns. To recruit participants, we sent our request to find participants who had experience with the Madrasati Platform via social media tools such as WhatsApp and Twitter. Participants who were interested in being part of the study sent us their contact. We per-formed interviews until thematic saturation were reached [49], as the last few interviews provided no new patterns or topics. A pilot study was conducted with one participant to ensure the clarity of the 
questions. As a result, the researcher decided to ask the participants to share their screen while using the Madrasati Platform which helped in providing more information about what the participants would like to express (see Fig. 2). All interviews were conducted online using Microsoft Teams. Each interview lasted between 40 minutes and one hour. To ensure consistency throughout all sessions, an interview guide was created. All participants gave their informed consent to be audio-recorded and participate in the study. The participants were given a brief explanation of the technique before the interviews began. The subjects discussed during the interviews were background information, teaching and technical experience, interface design issues, challenges, and suggestions for improvement. All the interviews were done in Arabic by the same inter-viewer, who wrote notes, audiorecorded and transcribed the conversation. The transcript was translated to English and reviewed by two linguistic experts (English and Arabic).

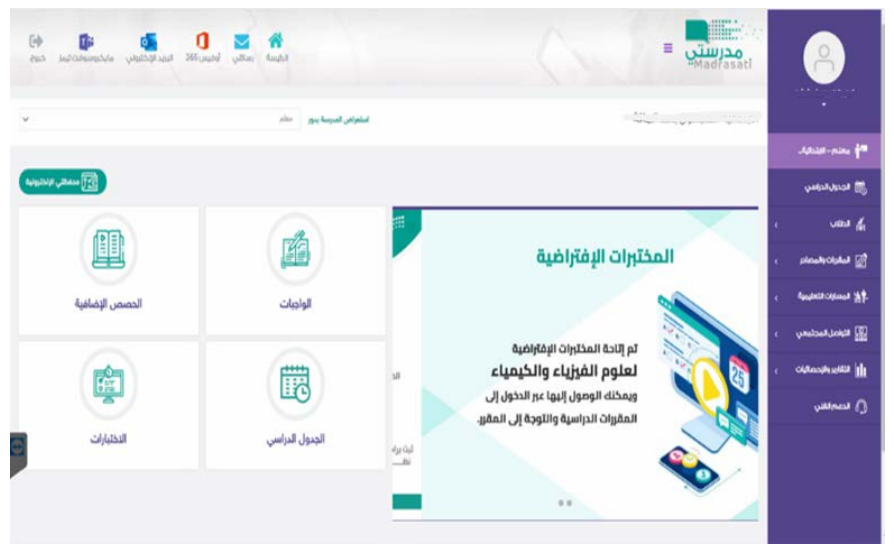

Fig. 2. A Screenshot of the Madrasti Platform from a Teacher Account.

\section{Thematic Analysis}

The researcher used Braun and Clarke's thematic analysis approach (see Table I) to analyze the qualitative data [50]. A method for detecting, analyzing, and reporting patterns (themes) within data is thematic analysis [50]. The thematic analysis was conducted using Nvivo, a qualitative data analysis software tool.

The researcher familiarized herself with the data by looking over it twice and collecting notes in the first step of the analysis. The noteworthy features in data were coded in a systematic manner across the full data set in the second stage, and data relevant to each code was gathered. The third stage was to group the codes into possible topics. According to [51], researchers should code 10-50 percent of the data first, and then have another coder confirm the coding reliability. The researcher used this suggestion to examine $25 \%$ of the data and create early coding groups and definitions. After then, the data was given to an independent coder to double-check. The independent coder had prior qualitative coding experience but had no prior knowledge of the subject. The researcher and the independent coder reviewed the themes in the fourth step to make sure they functioned with the coded extracts and the whole data set. After that changes were made to improve the coding scheme. The researcher continued to code the rest of the data after refining the technique. The topics were given names and descriptions in the fifth step. A scholarly report on the analysis was created as the final phase. The independent coder then double-checked all the segmentations and coding. Both the researcher and the independent coder collaborated to discuss and resolve issues, as well as to come up with the final category names.

\section{TABLE I. THEMATIC ANALYSIS’S Phases [50]}

1. Familiarization with the data
2. Generating initial codes
3. Searching for themes
4. Reviewing themes
5. Defining and naming themes
6. Producing the report

\section{RESULTS}

The results of the questionnaire and the interviews are presented in this section.

\section{A. Participants}

A total of 759 participants responded to the questionnaire and $20 \%$ of them were male while $80 \%$ were female. $12.6 \%$ were between the ages of 26 and 35; 35.1\% were between the ages of 36 and 45; 32.4\% were between the ages of 46 and 55; and $1.6 \%$ were beyond 55 . In addition, most of the participants (71.3\%) had teaching experience of more than 10 years. $42 \%$ were teaching the primary level, $26.6 \%$ were teaching the intermediate level, $24.6 \%$ were teaching the secondary level and $6.4 \%$ were teaching more than one level. Also, $37.7 \%$, 34.8\% and $7.9 \%$ of the participants were from Riyadh region, Makkah region and Madinah region, respectively. Moreover, 61.5\% of participants reported that they never been utilized any e-learning systems previously. Furthermore, Google Chrome was the browser used with the Madrasati Platform by 64\% of the participants. 20.7\% used Microsoft Edge and 7.8\% used Safari. Finally, 552 teachers (72.7\%) used the Madrasati Platform via laptops, $10.3 \%$ via tablets or iPads, $11.9 \%$ via mobiles and only $5.1 \%$ via desktops. Table II provides an overview of the descriptive statistics of the participants.

For the interviews, it was conducted with ten teachers who agreed to participate with ages ranged from 34 to 45 years. $70 \%$ of the interviewees had a bachelor's degree, $20 \%$ had a master's degree and 10\% had a diploma. Moreover, $40 \%$ of interviewees were teaching the secondary level, 30\% were teaching the primary level, and $30 \%$ were teaching the intermediate level. Also, $80 \%$ of the interviewee had a teaching experience of more than 10 years.

\section{B. CSUQ}

Fig. 3 shows the average response to each item in the CSUQ questionnaire from all participating teachers. Numbers range from 1 to 7 , with lower scores indicating a higher satisfaction level. The average of teachers replies to the statements range between 2.61 and 3.97. The overall score of the CSUQ, as well as the scores of the three subfactors: System Usefulness, Information Quality, and Interface Quality, are shown in Fig. 4. The CSUQ's overall score was $3.14(\mathrm{SD}=1.97)$ and the three subfactors had average scores of 2.83, 3.41, and 3.25, respectively. 
TABLE II. SUMMARY STATISTICS ON PARTICIPANT DEMOGRAPHICS

\begin{tabular}{|c|c|c|c|}
\hline $\begin{array}{l}\text { Demographic } \\
\text { Attributes }\end{array}$ & & $\begin{array}{l}\text { Number of } \\
\text { respondents }\end{array}$ & $\%$ \\
\hline \multirow[t]{2}{*}{ Gender } & Male & 152 & 20 \\
\hline & Female & 607 & 80 \\
\hline \multirow[t]{5}{*}{ Age } & $<25$ & 2 & .3 \\
\hline & $26-35$ & 96 & 12.6 \\
\hline & $36-45$ & 403 & 53.1 \\
\hline & $46-55$ & 246 & 32.4 \\
\hline & $>55$ & 12 & 1.6 \\
\hline \multirow[t]{4}{*}{ Teaching Experience } & $<1$ & 2 & .3 \\
\hline & 1 year $>$ and $<5$ year & 31 & 4.1 \\
\hline & $\begin{array}{l}6 \text { years }>\text { and }<10 \\
\text { year }\end{array}$ & 185 & 24.4 \\
\hline & 10 years $>$ & 541 & 71.3 \\
\hline \multirow[t]{4}{*}{ School level } & Primary & 322 & 42.4 \\
\hline & Intermediate & 202 & 26.6 \\
\hline & Secondary & 187 & 24.6 \\
\hline & $>$ level & 48 & 6.4 \\
\hline \multirow[t]{11}{*}{ Region: } & Riyadh & 286 & 37.7 \\
\hline & Makkah & 264 & 34.8 \\
\hline & Eastern & 46 & 6.1 \\
\hline & Madinah & 60 & 7.9 \\
\hline & Al Baha & 2 & 0.3 \\
\hline & Qassim & 33 & 4.3 \\
\hline & Ha'il & 1 & 0.1 \\
\hline & Tabuk & 30 & 4.0 \\
\hline & Aseer & 14 & 1.8 \\
\hline & Jazan & 22 & 2.9 \\
\hline & Najran & 1 & 0.1 \\
\hline \multirow[t]{2}{*}{$\begin{array}{l}\text { Previously Use E- } \\
\text { learning System }\end{array}$} & Yes & 292 & 38.5 \\
\hline & No & 467 & 61.5 \\
\hline \multirow[t]{6}{*}{ Browser } & Google Chrome & 486 & 64 \\
\hline & Microsoft Edge & 157 & 20.7 \\
\hline & Safari & 59 & 7.8 \\
\hline & Firefox & 18 & 2.4 \\
\hline & internet explorer & 20 & 2.6 \\
\hline & Other & 19 & 2.5 \\
\hline \multirow[t]{4}{*}{$\begin{array}{l}\text { Device For Platform } \\
\text { Use }\end{array}$} & Desktop & 39 & 5.1 \\
\hline & Laptop & 552 & 72.7 \\
\hline & Tablet/iPad & 78 & 10.3 \\
\hline & Mobile & 90 & 11.9 \\
\hline
\end{tabular}

In order to determine the level of satisfaction, CSUQ scores were transformed to a 0-100-point scale from their previous scale of 1-7. This conversion is used in previous studies [40], [41] to convert CSUQ scores to SUS scores then the scores were matched against the Sauro-Lewis CGS (Table III). The process of this conversion is as follows:

- Taking the mean of the CSUQ items (16 separate items).

- minus 1 , and.

- multiplying by $100 / 6$.

- subtracted the result from 100.

For example: Using the best possible CSUQ mean of 1, the score converted to the SUS scale is: $100-(1-1)(100 / 6)=$ $100-0=100$.

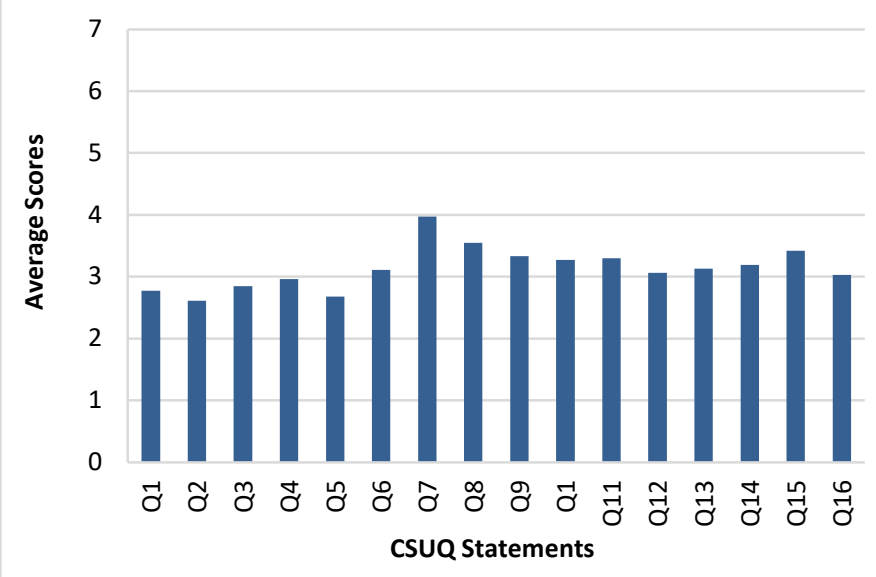

Fig. 3. Statement-by-Statement Comparison of CSUQ.

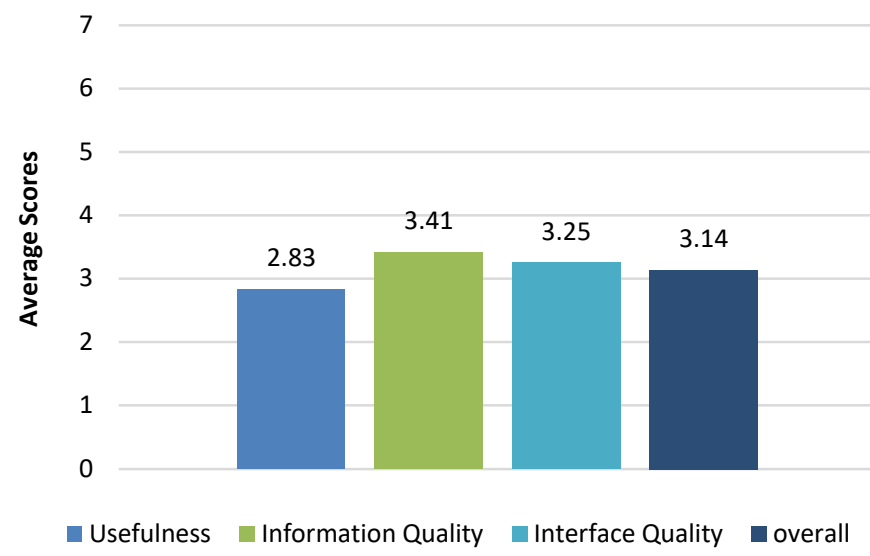

Fig. 4. Overall Score of CSUQ and the Three Scores of CSUQ Subfactors.

Table IV shows the converted scores for the CSUQ (overall and the three subfac-tors). The overall mean CSUQ was 64.36 (Grade: C-) which indicates that the Madrasati Platform has a low average of usability and teachers were not entirely satisfied with it. The converted scores for both Information Quality and Interface Quality are low (Grade: D) while the score of the Usefulness is within the average (Grade: C). 
TABLE III. ThE SAURO-LEWIS CURVED GRADING SCALE

\begin{tabular}{|l|l|l|}
\hline SUS score range & Grade & Percentile range \\
\hline $84.1-100$ & $\mathrm{~A}+$ & $96-100$ \\
\hline $80.8-84.0$ & $\mathrm{~A}$ & $90-95$ \\
\hline $78.9-80.7$ & $\mathrm{~A}-$ & $85-89$ \\
\hline $77.2-78.8$ & $\mathrm{~B}+$ & $80-84$ \\
\hline $74.1-77.1$ & $\mathrm{~B}$ & $70-79$ \\
\hline $72.6-74.0$ & $\mathrm{~B}-$ & $65-69$ \\
\hline $71.1-72.5$ & $\mathrm{C}+$ & $60-64$ \\
\hline $65.0-71.0$ & $\mathrm{C}$ & $41-59$ \\
\hline $62.7-64.9$ & $\mathrm{C}-$ & $35-40$ \\
\hline $51.7-62.6$ & $\mathrm{D}$ & $15-34$ \\
\hline $0.0-51.6$ & $\mathrm{~F}$ & $0-14$ \\
\hline
\end{tabular}

TABLE IV. CONVERTED SCORES FORTHECSUQ(OVERALL AND THE THREE SUBFACTORS)

\begin{tabular}{|l|l|l|l|}
\hline factor & Mean & Score range & Grade \\
\hline overall & 3.14 & 64.36 & C- \\
\hline Usefulness & 2.83 & 69.51 & C \\
\hline Information Quality & 3.41 & 59.80 & $\mathrm{D}$ \\
\hline Interface Quality & 3.25 & 62.52 & $\mathrm{D}$ \\
\hline
\end{tabular}

\section{Themes}

Table V shows the number of usability issues reported by interviewees. In total, 135 issues were reported. Seven themes emerged from the thematic analysis of the interviews. Table VI describes how each theme in this study is defined. $28.15 \%$ of the issues were about navigation theme and $26.67 \%$ were about missing features. Furthermore, 20\%, 11.11\% and $8.15 \%$ of the issues were about broken features, compatibility issues and system messages' issues, respectively. The lowest percentage of the issues was about inability of the platform to prevent errors with $4.44 \%$ and accessibility with $1.48 \%$.

Missing Features: All the ten interviewees proposed features that were missing but may help them use the Madrasati Platform more effectively. Features and example quotes include the following:

1) Assignment notification: "When students submit their assignments, they notify me with their submission via WhatsApp because there are no assignments notifications in the platform.” User4.
2) Synchronize the Madrasati Platform with the Noor system: "After we finish, we need to insert all grades in "Noor" system. Why is there no link between the two systems? It is double works for us." User2.

3) Download all files: "It is better if the platform provides the option to download all assignments as one file or a compressed file.” User9.

4) Message status Read/Unread: "When I go to the students' inquiries page, I don't remember which messages I read and which ones I didn't. There is no message status (read and unread) and this makes me check all messages each time.” User1.

5) Share questions with other schools: "There is no questions bank for my course, and I wish that I could share questions with other teachers who are teaching the same course in other schools. This will save our time.” User7.

6) Sort Assignments: "When I view students' assignments, I cannot sort them as what I need. It displays Assignments based on alphabetic of students' names. I would like to sort them based on the submission date." User8.

7) Submit project: "There is no option for students in the secondary level to submit their projects and we use Telegram for this.” User6.

8) Search filter by date in attendance report page: "In attendance report, I cannot search by date or by the class, only search by status is available.” User3.

9) Synchronize the Madrasati Platform with Microsoft Team: "Taking attendance for each class is exhausting and it is hard especially when I have two continuous classes. Why the platform is not linked with Teams and can take the attendance automatically." User9.

10)Charts and Graphs: "The report pages not comfortable to our eyes because all statistics are represented as numbers and texts. It is too much information here. Using charts and graph is preferable.” User10.

11)Help and support documents: "The platform lacks help documents, if I faced any problem; I go to YouTube to see what people who have the same problem do." User5.

12)Save Session: "When I start to prepare the session and I go to add assignment and come back to my session again. I do not find it because there is no save session option, so I have to recreate it again.” User7.

TABLE V. NUMBER OF THEMESEMERGED BY EACHUSER

\begin{tabular}{|l|l|l|l|l|l|l|l|l|l|l|l|l|}
\hline Themes & $\mathbf{U 1}$ & $\mathbf{U 2}$ & $\mathbf{U 3}$ & $\mathbf{U 4}$ & $\mathbf{U 5}$ & $\mathbf{U 6}$ & $\mathbf{U 7}$ & $\mathbf{U 8}$ & U9 & U10 & Total & $\mathbf{9}$ \\
\hline Missing features & 2 & 3 & 5 & 3 & 4 & 3 & 4 & 5 & 4 & 3 & 36 & 26.67 \\
\hline Broken features & 3 & 1 & 3 & 2 & 2 & 2 & 5 & 2 & 3 & 4 & 27 \\
\hline Navigation & 3 & 2 & 6 & 2 & 3 & 3 & 4 & 3 & 5 & 7 & 38 & 28.15 \\
\hline Accessibility. & 0 & 2 & 0 & 0 & 0 & 0 & 0 & 0 & 0 & 0 & 2 & 1.48 \\
\hline Preventing errors & 1 & 0 & 2 & 2 & 0 & 0 & 1 & 0 & 0 & 0 & 6 \\
\hline Compatibility & 1 & 1 & 3 & 3 & 2 & 1 & 1 & 0 & 2 & 1 & 15 & 11.11 \\
\hline System Messages & 3 & 3 & 1 & 2 & 1 & 0 & 1 & 0 & 0 & 0 & 11 & 8.15 \\
\hline Total of the issues & $\mathbf{1 3}$ & $\mathbf{1 2}$ & $\mathbf{2 0}$ & $\mathbf{1 4}$ & $\mathbf{1 2}$ & $\mathbf{9}$ & $\mathbf{1 6}$ & $\mathbf{1 0}$ & $\mathbf{1 4}$ & $\mathbf{1 5}$ & $\mathbf{1 3 5}$ & $\mathbf{1 0 0}$ \\
\hline
\end{tabular}


TABLE VI. THEMES' DEFINITIONS

\begin{tabular}{|ll|l|}
\hline \multicolumn{2}{|c|}{ Theme } & Definition \\
\hline 1) & $\begin{array}{l}\text { Missing } \\
\text { features }\end{array}$ & $\begin{array}{l}\text { Users face difficulties due to the absence of certain } \\
\text { functions }\end{array}$ \\
\hline 2) & $\begin{array}{l}\text { Broken } \\
\text { features }\end{array}$ & $\begin{array}{l}\text { Users face difficulties due to some current functions } \\
\text { not working, provide inaccurate result or cause delay } \\
\text { in work. }\end{array}$ \\
\hline 3) & Navigation & $\begin{array}{l}\text { Users have difficulty moving between pages or } \\
\text { selecting appropriate links for information or } \\
\text { function. }\end{array}$ \\
\hline 4) & Accessibility. & $\begin{array}{l}\text { Users with disabilities have difficulty contributing, } \\
\text { perceiving, comprehending, navigating, and } \\
\text { interacting with the platform. }\end{array}$ \\
\hline 5) & $\begin{array}{l}\text { Preventing } \\
\text { errors }\end{array}$ & $\begin{array}{l}\text { Users find the platform not helping them from } \\
\text { prevents a problem from occurring in the first place. }\end{array}$ \\
\hline 6) & Compatibility & $\begin{array}{l}\text { Users face difficulties when using specific browser or } \\
\text { specific device. }\end{array}$ \\
\hline 7) & $\begin{array}{l}\text { System } \\
\text { Messages }\end{array}$ & $\begin{array}{l}\text { User experienced unclear, wrong or useless error } \\
\text { message. Also, user does not receive a message or } \\
\text { feedback when it is required. }\end{array}$ \\
\hline
\end{tabular}

Broken Features: All the ten interviewees mentioned problems with the Madrasati Platform's present features. Some of the current features, such as motivational stars, grades, and academic records, are not working. Other features, such as system email, announcements, and a short time for automatically logging out, caused them to experience delays. Other issues were mentioned, such as lost assignment files and inaccurate teacher reports. Examples of quotes that mention those issues are as follows:

- "Teacher report is not accurate, and this is really annoying me because I add a lot of things, but the number in the report is not correct. I take pictures for what I did and send it to the leader of the school because she asks me about it, and she cannot see my efforts via the platform”. User9.

- "The auto logout is short and if have two continuous classes, I have to login twice." User3.

- 'If I add enrichments in enrichments' bank, it does not appear in the class, but it is counted in the report. And if I add it from my Timetable, it appears in my class but not counted in the report. So, I have to add it twice in the two places to make sure it will appear in both my report and my class." User10.

Navigation: The Madrasati Platform was difficult to navigate for all the ten interviewees. There were complaints about being unable to return to the previous page, duplications, and seeing assignments one by one. The concerns are described in the following quotes:

- "I can send assignment to students from two places. From my timetable and from my assignments. This is really confusing.” User7.

- "Back button is missing from many pages, and each time I have to click the main menu to go to the page that I want.” User10.

- "It is really hard viewing assignment one by one. I have six classes and each class has 40 students. I send assignments twice a week and downloading assignments one by one is time consuming." User9.

- "When I download the student's assignment, the file name is not meaningful and not related to students. So, when I need to find the specific student assignment, I have to navigate all of them." User3.

Accessibility: One teacher mentioned the content accessibility issues in the Madrasati Platform with her students who have a hearing impairment. The teacher mentioned the videos with no subtitles, sign language, or a summary. Examples of quotes that mention this issue are as follows:

- "In our school we have special classes for hearing impairment students. We summarize the content for them not like other students. But in the Madrasati Platform, the same content for all, even the videos there is no written summary next to them that can help those students.” User2.

- "The cartoon films without subtitle or the use of sign language. Thus, students go to Ein channel which has all videos in sign language”. User2.

Preventing errors: Four teachers shared examples of how the Madrasati Platform failed to prevent faults or mistakes from occurring. Drop down menus that are not synchronized, manual calculations, and duplicate sessions are all examples of issues. Examples of the quotes that mention this issue are as follows:

- "When I select the level in the first dropdown menu, I can select a course for another level from the next dropdown menu. In the second dropdown menu, I'm supposed to see only the courses related to the level that I have selected in the first dropdown menu." User1.

- "I have to calculate the number of minutes when I create the exams or session. It is better if the platform calculates it to avoid any mistakes or at least to give us another option like choose hours.” User3.

- "I can create the same session twice and this caused a lot of delay in waiting to move students to one of them." User4.

Compatibility: Nine teachers mentioned cases related to this theme. The Madrasati Platform was difficult to use via Google Chrome compared to other browsers. Also, some problems were mentioned when using mobile phones or tablets. The issues are described in the following quotes:

- "We prefer to use Google Chrome, but we had a problem with it. It keeps saving the data and we cannot use different accounts even when delete the data. To solve this problem, we create many accounts in the same laptop, one for me, one for my husband and one for our son and one for our daughter.” User4.

- "I usually use Google Chrome but with the Madrasati Platform, I found that Microsoft Edge is better. I faced many problems with Google Chrome, the system hangs a lot with it” User2. 
- "I cannot use specific types of questions like matching question. It will not work effectively in mobile or tablets.” User5.

System Message: Six teachers expressed issues with the system's messages and responses. Some error messages were unclear, there was no system reaction, and there was a lack of problem explanation in the message. The concerns are described in the following quotes:

- "The system shows me errors in creating assignment, but I don't know what the reason is or how I can solve it. I only try again and again.” User1.

- "I have uploaded the file, but no message tells me its uploaded. Then, when I refresh the page, the file is there.” User7.

- "I found that if I uploaded a large image, the message does not tell me you uploaded a big file and by guessing I know that this is the reason.” User4.

- "Some error messages have ambiguous codes, and I don’t understand it.” User3.

\section{DisCUSSION}

This section discusses the study's findings, as well as their relevance to other studies. The goals of this study were to determine the usability of a Madrasati Platform from the perspective of schoolteachers in Saudi Arabian, as well as to identify the most common usability concerns that teachers encountered when using the platform.

The first research question aims to investigate how teachers perceived the Madrasati Platform in terms of usability. A total of 759 teachers from different regions in Saudi Arabia responded to the CSUQ in our study. The CSUQ's mean total score was 64.63 , which was lower than expected. Based on this finding, it seems that the usability of the Madrasati Platform on the teacher side is inadequate and needs to be improved. Comparing this result with the findings of the study with the Madrasati Platform in a different context, it is consistent with the research of [7] which reported that students' pages in the Madrasti Platform had several issues in terms of usability. Looking to the three subscales of the CSUQ, the results show that the acceptable mean score for the Usefulness while the scores are lower than expected for both Information Quality and Interface Quality. These findings are similar to the results of [40] when evaluating the usability of the Blackboard using CSUQ.

The second study question was to determine the most significant usability concerns that teachers had when using the Madrasati Platform. Teachers found the Madrasati Platform difficult to navigate. There were concerns about inability to access the previous pages and many duplications. Navigation is a critical issue and requires more considerations which have an impact on user satisfaction and continuity with e-learning systems [52]. Comparing this result with the findings of previous research in a different context, it is consistent with the research of [40] which found that the navigation is a significant issue on the Blackboard by the instructors. Teachers in our study also complain about functions that are not working. As previously stated, the system was developed throughout the epidemic, and the Ministry of Education made numerous updates and improvements during that time [53]. Working on the system for such a short period of time may not be sufficient to carefully test the functionalities that have been reported as broken. Furthermore, teachers mentioned other usability difficulties, such as the platform's inability to prevent them from making mistakes and issues with the platform's messages and responses. Unclear error messages, a lack of problem explanation in the message, and manual calculations that allow for human error are just a few examples. This result is in line with [54] which examined the usability of Khan Academy and found the major issues in "Error Prevention" when the system does not prevent users from making errors and users don't get properly informed in the state of error. Moreover, the Madrasati Plat-form's content accessibility concern for students with hearing impairment was identified. Subtitles, sign language, and videos brief summaries are not supported on the Madrasati Platform. This finding is consistent with prior research by [7], who found that the Madrasti platform is inaccessible to some disabled users. Based on the findings, the present study's recommendations for enhancement are as follows:

- It is necessary to conduct extensive testing of the platform's functions, and bro-ken features should be marked as inactive.

- It is advised to connect the Madrasati Platform to the Noor system to assess students immediately.

- Madrasati Platform developers are encouraged to follow the World Wide Web Consortium (W3C) guidelines to ensure that people with disabilities have the same access to information on the platform as everyone else.

- Access to the previous and next pages should be made easier for the user. Adding "Back" and "Next" buttons, for example, will be beneficial.

- The Madrasati Platform should offer appropriate help online and provide documentation that is easily accessible and searchable.

- It is suggested to reduce the amount of text in the page by using graphs and charts in the statistical and reports pages.

- It is recommended to include sign language in the content provided by a video and to employ cartoon films with subtitles. Also, next to each video, include a summary in writing.

- It is suggested to integrate the Teams program and Madrasati Platform. As a result, student attendance and absence records on the Platform will be immediately linked to the Teams program.

- Eliminate redundancy on the platform whenever possible to reduce cognitive overload and confusion.

- A database for scientific material, such as assignments and tests, should be available. 
- Replace human calculations with system calculations and synchronize corresponding dropdown menus to prevent users from selecting the incorrect option.

- it is recommended that the platform should not use jargon in messages to pro-vide clear and understandable helping messages.

- The number of clicks required to access any page should be kept to a minimum. For example, send assignment button can be added in the create assignment page.

- It is advised to increase the duration time for the automatically logout.

- It is essential to enhance the search by adding common search features and filters.

- Allow users to download all files at once to save time downloading large numbers of files one at a time.

- Adding features such as assignment notification, sort assignment, share question with other schools, message status and submit project will be useful.

- Continuous user feedback will improve Madrasati Platform's usability and acceptability in schools.

The outcomes of this study contribute to the fields of elearning system and usability evaluation in a variety of ways. The research provided here is the first to assess Madrasati Platform's perceived usability from the perspective of schoolteachers and make recommendations based on the findings. The findings have significant implications for elearning system usability. It will aid the Saudi Ministry of Education in developing policies and programs that will ensure the success of e-learning in the kingdom.

\section{LIMITATIONS}

It is important to mention that generalizability of the findings has limitations. First, the participants of the study were all recruited from a single target group: teachers. While this has not hampered our research because they are one of the primary target groups for the system being examined, it may limit the applicability of the findings to other groups who use it. Second, the data collecting methods in this study were a standardized usability questionnaire and semi-structured interviews. It would be interesting to know if data gathered from traditional usability research showed consistent results. Third, the study was conducted during the pandemic since the Madrasti Platform is still new to most teachers and they are unfamiliar with it. The results may change when teachers become more familiar with the platform.

\section{VII.CONCLUSION}

The Madrasati Platform is a new system for all school levels in Saudi Arabia that was developed by the Saudi Ministry of Education during the covid-19 pandemic. Usability is one of the most important characteristics of a system since it affects how users interact with it. Therefore, in this paper, we examined the usability level of the Madrasati Platform from the perspective of schoolteachers in Saudi
Arabia, as well as the most common usability difficulties that teachers encountered when using the platform. Both questionnaires and semi-structured interviews were conducted to collect the data. According to the study's findings, the Madrasati Platform's usability in schools for teachers is insufficient and should be improved further. Teachers stated many usability issues faced by using the Madrasati platform such as navigation, broken features, inability of the platform to prevent user mistakes to occur, message error issues, compatibility issues and content accessibility issues for the disability users. Additionally, a list of recommendations for enhancement was presented based on those findings. For future work, evaluation of the Madrasati Platform's usability with other target groups, such as students, school leaders, and parents, is helpful. Also, examine into whether the demographics of users have an impact on the total CSUQ scores. Furthermore, combination of evaluation methods, such as focus group, heuristic evaluation, and eye tracking, would be useful. Moreover, examination of other usability factors, such as memorability, learnability and accessibility, would be valuable in the future.

\section{REFERENCES}

[1] O. Alhadreti, "A Comparative Usability Study of Blackboard and Desire2Learn: Students' Perspective,” Jul. 2020, vol. 12205 LNCS, pp. 3-19, doi: 10.1007/978-3-030-50513-4_1.

[2] H. H. Adelsberger, B. Collis, and J. M. Pawlowski, Handbook on information technologies for education and training. Springer Science \& Business Media, 2013.

[3] LMS Market, "LMS Market Size by Solutions \& Services - 2025 MarketsandMarkets,” 2020. https://www.marketsandmarkets.com/ Market-Reports/learning-management-systems-market-

1266.html?gclid=EAIaIQobChMI2KTGv93D8QIVxe7tCh2MWQhaEA AYASAAEgJK5vD_BwE (accessed Jul. 02, 2021).

[4] U. T. Alturki and A. Aldraiweesh, "Evaluating The Usability And Accessibility Of LMS 'Blackboard' At King Saud University," Contemp. Issues Educ. Res. Quart., vol. 9, no. 1, pp. 33-44, 2016, doi: https://doi.org/10.19030/cier. v9i1.9548.

[5] A. R. Khanfar, "Distance-learning entrepreneurship education in the time of corona virus-COVID-19 challenges \& solution,” J. Entrep. Educ., vol. 23, pp. 1-17, 2020.

[6] P. Sahu, "Closure of Universities Due to Coronavirus Disease 2019 (COVID-19): Impact on Education and Mental Health of Students and Academic Staff," Cureus, vol. 12, no. 4, Apr. 2020, doi: 10.7759/cureus.7541.

[7] J. M. Alamri and S. S. Almoaiqel, "Evaluating Usability for e-Learning 'Madrasati' Platform in Saudi Arabia,” vol. 12, no. 6, pp. 1492-1507, 2021, doi: https://doi.org/10.17762/turcomat.v12i6.2688.

[8] M. Alashwal, "Assessing Online Teaching in Higher Education Amid the COVID-19 Pandemic: A Case Study from Saudi Arabia," in ConScienS, 2020, p. 68, doi: 10.5281/zenodo.4058780.

[9] Unesco, “COVID-19 Educational Disruption and Response," 2020. https://en.unesco.org/news/covid-19-educational-disruption-andresponse (accessed Jun. 18, 2021).

[10] H. M. Abouelnaga et al., "A Survey on Educational Technology in Saudi Arabia,” Int. J. Appl. Eng. Res., vol. 14, no. 22, pp. 4149-4160, 2019, Accessed: Jun. 18, 2021. [Online]. Available: http://www.ripublication.com.

[11] W. Bao, "COVID-19 and online teaching in higher education: A case study of Peking University,” Hum. Behav. Emerg. Technol., vol. 2, no. 2, pp. 113-115, 2020, doi: https://doi.org/10.1002/hbe2.191.

[12] M. Alashwal, "Faculty Perceptions and Use of Web 2.0 Tools in Saudi Arabian Higher Education,” 2019. Accessed: Jun. 18, 2021. [Online]. Available: https://stars.library.ucf.edu/etd/6310.

[13] K. Tuqa, "Distance learning amid coronavirus to help school dropouts in Saudi Arabia: Minister | Al Arabiya English,” alarabiya, 2020. 
https://english.alarabiya.net/coronavirus/2020/05/15/Distance-learningamid-coronavirus-to-help-school-dropouts-in-Saudi-Arabia-Minister (accessed Jun. 16, 2021).

[14] A. Bashraheel, "Saudi Education Ministry takes on distance learning of 6 million students in 10 days," Arabnews, 2020. https://www.arabnews.com/node/1648561/saudi-arabia (accessed Jun. 16, 2021).

[15] M. Z. Hoq, "E-Learning During the Period of Pandemic (COVID-19) in the Kingdom of Saudi Arabia: An Empirical Study,” Am. J. Educ. Res., vol. 8, no. 7, pp. 457-464, 2020, doi: 10.12691/education-8-7-2.

[16] H. Al-Mayman, "Saudi e-learning portal ushers in 'new normal' with virtual classrooms,” 2020. https://www.arabnews.com/node/1730541/ saudi-arabia (accessed Jun. 17, 2021).

[17] Saudi24news, "Modifying the administrative staff's work hours in the intermediate and secondary stages | Saudi 24 News,” 2020. https://www.saudi24news.com/2020/08/modifying-the-administrativestaffs-work-hours-in-the-intermediate-and-secondary-stages.html (accessed Jun. 16, 2021).

[18] K. AlSalih, "Saudi Study for Assessment of Remote Learning Process," Alwatan Newspaper., 2020. https://www.alwatan.com.sa/article/ 1048932 (accessed Jun. 21, 2020).

[19] Saudi Gazette report, "E-learning may be strategic choice post-corona crisis: Saudi minister,” Saudi Gazette, 2020. https://saudigazette.com.sa/article/592102 (accessed Apr. 20, 2020).

[20] H. M. Alwahoub, M. N. L. Azmi, and N. J. Jomaa, "Teachers' and Students' Perceptions of E-Learning Integration in the Primary Schools of Saudi Arabia,” Int. J. Adv. Res. Educ. Soc., vol. 2, no. 1, pp. 116126, 2020, [Online]. Available: http://myjms.moe.gov.my/index. php/ijares.

[21] Madrasati, "Ministry of Education, Kingdom of Saudi Arabia.," 2020. https://backtoschool.sa/ (accessed Jun. 16, 2021).

[22] B. Aldossry, "Evaluating The Madrasati Platform for the Virtual Classroom in Saudi Arabian Education during the Time of Covid-19 Pandemic,” Eur. J. Open Educ. E-learning Stud., vol. 6, no. 1, 2021, doi: http://dx.doi.org/10.46827/ejoe.v6i1.3620.

[23] MOE, "Kingdom of Saudi Arabia," Ministry of Education, 2020. https://www.moe.gov.sa/ar/mediacenter/MOEnews/Pages/MR2-2020453.aspx (accessed Feb. 22, 2021).

[24] M. Andergassen et al., "The evolution of e-learning platforms from content to activity based learning: The case of Learn@WU,” in Proceedings of 2015 International Conference on Interactive Collaborative Learning, ICL 2015, Nov. 2015, pp. 779

[25] R. Manna, “'Effective learning through e-learning system: DEA Approach': HCI technologies for education," 2012, doi: 10.1109/IHCI.2012.6481851.

[26] S. Ikemoto, Y. Takai, and N. Kuwahara, "Creation and Usability Evaluating of E-Learning Contents for Automobile Repair Block Painting,” IJACSA) Int. J. Adv. Comput. Sci. Appl., vol. 8, no. 12, pp. 333-337, 2017, Accessed: Jun. 16, 2021. [Online]. Available: www.ijacsa.thesai.org.

[27] S. E. Van Nuland and K. A. Rogers, "The anatomy of E-Learning tools: Does software usability influence learning outcomes?,” Anat. Sci. Educ., vol. 9, no. 4, pp. 378-390, Jul. 2016, doi: 10.1002/ase.1589.

[28] M. R. Davids, M. L. Halperin, and U. M. E. Chikte, "Optimising cognitive load and usability to improve the impact of e-learning in medical education,” African J. Heal. Prof. Educ., vol. 7, no. 2, p. 147, Nov. 2015, doi: 10.7196/ajhpe.659.

[29] A. O. Elfaki, Y. Duan, R. Bachok, W. Du, M. G. M. Johar, and S. Fong, "Towards measuring of e-learning usability through user interface," in Proceedings - 2nd IIAI International Conference on Advanced Applied Informatics, IIAI-AAI 2013, 2013, pp. 192-194, doi: 10.1109/IIAIAAI.2013.17.

[30] R. Schulz, G. M. Isabwe, and F. Reichert, "Supporting teachers' needs within and through e-learning systems," Jan. 2014, doi: 10.1109/ICWOAL.2014.7009228.

[31] I. S. Junus, H. B. Santoso, R. Y. K. Isal, and A. Y. Utomo, "Usability evaluation of the student centered e-Learning environment," Int. Rev. Res. Open Distance Learn., vol. 16, no. 4, pp. 62-82, 2015, doi: 10.19173/irrodl.v16i4.2175.
[32] M. R. Davids, U. M. E. Chikte, and M. L. Halperin, "Effect of improving the usability of an e-learning resource: A randomized trial," Adv. Physiol. Educ., vol. 38, no. 2, pp. 155-160, 2014, doi: 10.1152/advan.00119.2013.

[33] N. Hollender, C. Hofmann, M. Deneke, and B. Schmitz, "Integrating cognitive load theory and concepts of human-computer interaction," Computers in Human Behavior, vol. 26, no. 6. Elsevier Ltd, pp. 12781288, Nov. 01, 2010, doi: 10.1016/j.chb.2010.05.031.

[34] J. Brooke, “SUS: A Retrospective,” J. Usability Stud., vol. 8, no. 2, pp. 29-40, 2013.

[35] J. R. Lewis, J. Brown, and D. K. Mayes, "Psychometric Evaluation of the EMO and the SUS in the Context of a Large-Sample Unmoderated Usability Study,” Int. J. Hum. Comput. Interact., vol. 31, no. 8, pp. 545553, Aug. 2015, doi: 10.1080/10447318.2015.1064665.

[36] J. Sauro and J. R. Lewis, Quantifying the user experience: Practical statistics for user research. Morgan Kaufmann, 2016.

[37] J. Sauro and J. R. Lewis, "Correlations among prototypical usability metrics: Evidence for the construct of usability," in Conference on Human Factors in Computing Systems - Proceedings, 2009, pp. 16091618, doi: $10.1145 / 1518701.1518947$.

[38] J. R. Lewis, "IBM Computer Usability Satisfaction Questionnaires: Psychometric Evaluation and Instructions for Use," Int. J. Hum. Comput. Interact., vol. 7, no. 1, pp. 57-78, 1995, doi: 10.1080/10447319509526110.

[39] J. Brooke, "SUS-A quick and dirty usability scale," London, UK: Taylor \& Francis.: In P. Jordan, B. Thomas, \& B. Weerdmeester (Eds.), 1996, pp. 189-194.

[40] O. Alhadreti, “Assessing Academics' Perceptions of Blackboard Usability Using SUS and CSUQ: A Case Study during the COVID-19 Pandemic,” Int. J. Hum. Comput. Interact., vol. 37, no. 11, pp. 10031015, 2021, doi: 10.1080/10447318.2020.1861766.

[41] J. R. Lewis, "Measuring Perceived Usability: The CSUQ, SUS, and UMUX,” Int. J. Hum. Comput. Interact., 2018, doi: 10.1080/10447318.2017.1418805.

[42] H. Al-Khalifa, "A First Step in Evaluating the Usability of JUSUR Learning Management System Arabic indoor navigation system for blinds View project A First Step in Evaluating the Usability of JUSUR Learning Management System,” 2010. Accessed: Jun. 13, 2021. [Online]. Available: https://www.researchgate.net/publication/ 267383219.

[43] K. Al-Omar, "Automated Usability Evaluation of E-Learning Websites in Saudi Arabia,” pp. 1-10, 2017, doi: 10.5121/csit.2017.70801.

[44] K. Al-Omar, "Evaluating the Internal and External Usability Attributes of E-Learning Websites in Saudi Arabia,” Adv. Comput. An Int. J., vol. 8, no. 4, 2017, doi: 10.5121/acij.2017.8401.

[45] M. Benaida, A. Namoun, and A. Taleb, "Evaluation of the Impact of Usability in Arabic University Websites: Comparison between Saudi Arabia and the UK Article in," IJACSA) Int. J. Adv. Comput. Sci. Appl., vol. 9, no. 8, 2018, doi: 10.14569/IJACSA.2018.090848.

[46] A. Alghafis, A. Alghafis, A. Alrasheed, and A. Abdulghany, "A Study on the Usability of Moodle and Blackboard - Saudi Students Perspectives,” iJIM, vol. 14, no. 10, pp. 159-165, 2020, doi: s https://doi.org/10.3991/ijim.v14i10.14381.

[47] J. Lazar, J. H. Feng, and H. Hochheiser, Research methods in humancomputer interaction. Morgan Kaufmann, 2017.

[48] B. A. AlGhannam, S. A. Albustan, A. A. Al-Hassan, and L. A. Albustan, "Towards a standard arabic system usability scale: Psychometric evaluation using communication disorder app,” Int. J. Human-Computer Interact., vol. 34, no. 9, pp. 799-804, 2018, doi: https://doi.org/10.1080/10447318.2017.1388099.

[49] G. Guest, A. Bunce, and L. Johnson, "How many interviews are enough? An experiment with data saturation and variability,” Field methods, vol. 18, no. 1, pp. 59-82, 2006, doi: https://doi.org/10.1177/1525822X05279903.

[50] V. Braun and V. Clarke, "Using thematic analysis in psychology,” Qual. Res. Psychol., vol. 3, no. 2, pp. 77-101, 2006, doi: 10.1191/1478088706qp063oa. 
[51] P. Mayring, "Qualitative content analysis forum qualitative sozialforschung," in Forum: qualitative social research, 2000, vol. 1, no. 2, p. 2.

[52] A. I. Gunesekera, Y. Bao, and M. Kibelloh, "The role of usability on elearning user interactions and satisfaction: a literature review," Journal of Systems and Information Technology, vol. 21, no. 3. Emerald Group Holdings Ltd., pp. 368-394, Oct. 21, 2019, doi: 10.1108/JSIT-02-20190024.
[53] Saudi24news, "News $24 \mid$ These are the most prominent new services on the 'Madrasati' platform in the second semester | Saudi 24 News,” 2021. https://www.saudi24news.com/2021/02/news-24-these-are-the-mostprominent-new-services-on-the-madrasati-platform-in-the-secondsemester.html (accessed Jun. 29, 2021).

[54] Maham Sheikh, Abdul Hafeez Muhammad, and Quadri Noorul hasan Naveed, "Enhancing Usability of E-Learning Platform: A Case Study of Khan Academy," sjesr, vol. 4, no. 2, pp. 40-50, May 2021, doi: 10.36902/sjesr-vol4-iss2-2021(40-50). 